\title{
Spontan koronar arteriedisseksjon
}

\author{
Spontan koronar arteriedisseksjon er en uvanlig årsak til akutt koronar- \\ syndrom og plutselig hjertedød. Tilstanden er vanligst hos yngre til \\ middelaldrende kvinner. Spontan koronar arteriedisseksjon skiller seg \\ betydelig fra aterosklerotisk hjertesykdom når det gjelder etiologi, epi- \\ demiologi og behandling. Pasienter med denne tilstanden har få risiko- \\ faktorer på aterosklerotisk hjertesykdom og generelt bedre prognose.
}

\author{
Charlotte Sæland \\ charlottesaland@gmail.com \\ Tor Melberg \\ Nigussie Bogale \\ Kardiologisk avdeling \\ Stavanger universitetssjukehus
}

Engelsk oversettelse på www.tidsskriftet.no
Spontan koronar arteriedisseksjon (SCAD) er en ikke-aterosklerotisk årsak til akutt koronarsyndrom. Tilstanden skiller seg markant i etiologi, behandling og prognose fra aterosklerotisk hjertesykdom. Den kjennetegnes ved ikke-traumatisk og ikke-iatrogen disseksjon av koronararterieveggen, med fravær av aterosklerose i koronarkarene. Dette er en uvanlig årsak til akutt koronarsyndrom og plutselig hjertedød i den generelle befolkningen.

Spontan koronar arteriedisseksjon ses hyppigest hos yngre til middelaldrende kvinner (1-3), og man kan nok anta at tilstanden er noe underdiagnostisert. Det typiske angiografiske utseendet er ikke alltid til stede, og det kan da være behov for supplerende undersøkelser med avansert bildediagnostikk. I de gjeldende retningslinjer for behandling av aterosklerotisk akutt koronarsyndrom anbefales tidlig perkutan koronar intervensjon (PCI) av aktuelle koronarkar, men det mangler spesifikke retningslinjer for spontan koronar arteriedisseksjon.

Det finnes relativt få studier om spontan koronar arteriedisseksjon, og pasienttallet i de som finnes er lavt. Tilstanden er ikke tidligere godt beskrevet i Norge. Ved Stavanger universitetssjukehus har vi sett flere tilfeller. Formålet med denne artikkelen er å gjøre tilstanden mer kjent, med tanke på å sikre adekvat behandling for pasientgruppen.

Artikkelen er bygd på litteratursøk i PubMed og forfatternes egne kliniske erfaring.

\section{Etiologi og diagnose}

Spontan koronar arteriedisseksjon er sannsynligvis årsak til $0,1-1,1 \%$ av tilfellene av akutt koronarsyndrom $(1,2)$. På verdensbasis er det rapportert under 800 tilfeller siden den første obduksjonsrapporten om tilstanden kom i 1931 (3-5). Hos kvinner under 50 år er imidlertid spontan koronar arteriedisseksjon årsak til akutt koronarsyndrom hos nær $25 \%$ (6).

Etiologien er uklar, og tilstanden er forsøkt forklart ved hjelp av to forskjellige mekanismer. Den første beskrives som rift $\mathrm{i}$ karveggens tunica intima, med videre dis- seksjon av karveggens tunica media. Den andre mekanismen forklares som hematomutvikling i karveggens tunica media etter rumpert vasa vasorum (de små karene som forsyner åreveggen) med videre danning av falskt lumen. Begge mekanismene vil føre til kompresjon av ekte karlumen og påfølgende myokardiskemi og hjerteinfarkt.

Forandringene kan bli mistolket som aterosklerose på angiografisk undersøkelse, spesielt hvis klassisk dobbeltlumenkontrastavfarging $i$ arterieveggen mangler $(3,7,8)$. Er man da i tvil om diagnosen hos en klassisk pasient, for eksempel en yngre kvinne uten risikofaktorer, kan man supplere med intrakoronar diagnostikk, som optisk koherens-tomografi (optical coherence tomography, OCT) og/eller intravaskulær ultralyd (IVUS) i tillegg til konvensjonell koronarangiografi (8).

\section{Angiografisk diagnose}

Spontan koronar arteriedisseksjon slik det ses ved konvensjonell koronarangiografi deles inn i tre typer.

Den første typen beskrives som et klassisk bilde med dobbelt lumen, hvor man får kontrastavfarging $\mathrm{i}$ arterieveggen med flere gjennomlysbare lumen. I en studie av Saw og medarbeidere (5) representerte dette $29 \%$ av alle tilfellene av spontan koronar arteriedisseksjon.

Den andre typen beskrives angiografisk som lang, diffust stenotisk utseende med varierende alvorlighetsgrad av stenose. Den representerte $67 \%$ av pasientene i samme studie (5).

Type 3 er ateroskleroseimitatoren, på grunn av angiografisk utseende som fokal og tubulær stenose. Den krever optisk koherenstomografi eller intravaskulær ultralydundersøkelse for å kunne stille riktig diagnose. Denne siste typen representerte 3,9\% av studiepasientene $(5,9)$ (fig 1).

\section{Pasientkarakteristikk}

Pasienter med spontan koronar arteriedisseksjon er oftest yngre til middelaldrende kvinner av kaukasisk etnisitet. Nyere studier har imidlertid vist at det er et større alderssprang

\section{HOVEDBUDSKAP}

Spontan koronar arteriedisseksjon er en sjelden årsak til akutt koronarsyndrom, men tilstanden ses ofte hos yngre til middelaldrende kvinner uten $ø$ kt risiko for aterosklerotisk hjertesykdom

Diagnosen krever at det ikke foreligger nevneverdig aterosklerose i koronarkar

Spontan koronar arteriedisseksjon er ofte assosiert med tilstander som fibromuskulær dysplasi og bør utelukkes ved takotsubokardiomyopati

Ved god blodstrøm i koronarkaret, stabil hemodynamikk og sikker diagnose skal pasienten hovedsakelig behandles konservativt 


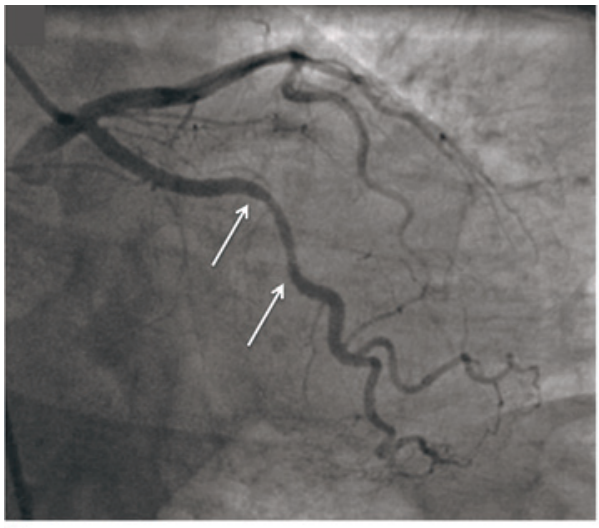

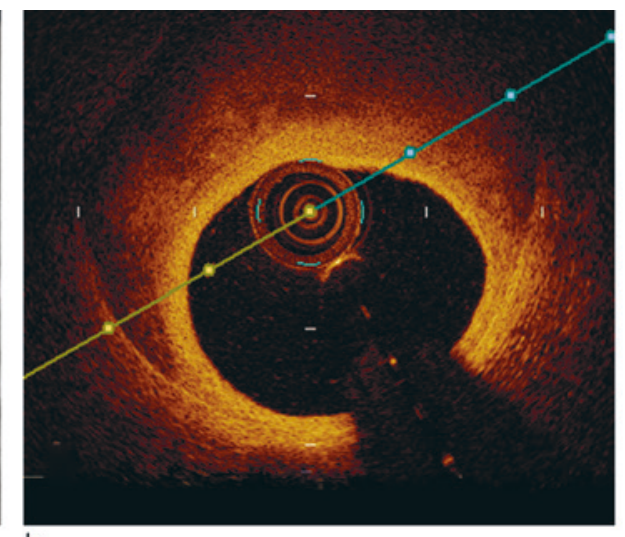

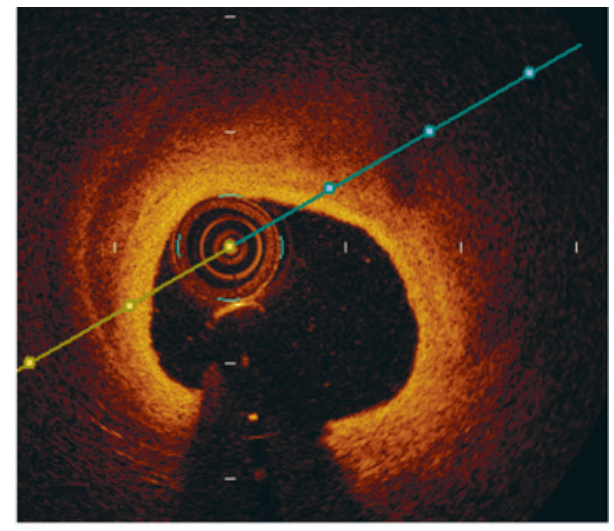

c

Figur 1 Spontan koronar arteriedisseksjon type 3. a) Moderat stenose av midtre ramus cirkumflexus-arterie (mellom piler) på grunn av spontan koronar arteriedisseksjon. b. c) Intramuralt hematom i falskt lumen på optisk koherens-tomografi i samme lesjon. Figuren er reprodusert med tillatelse fra AME Publishing Company (9)

enn tidligere antatt, med en stor andel postmenopausale kvinner. Det er lavere forekomst hos menn (5).

Pasientgruppen har ofte kun hypertensjon som koronar risikofaktor. Innleggelsesårsaken er brystsmerter med typiske kliniske tegn som ved vanlig akutt koronarsyndrom $(5,7,10,11)$.

Studier viser at opptil $50 \%$ av pasientene har EKG-forandringer med ST-heving (10). Ekkokardiografi viser som regel god venstre ventrikkel-funksjon $(7,10,11)$. Pasientene har ofte vært utsatt for emosjonelt eller fysisk stress i forkant av hendelsen $(7,10)$. Venstre fremre koronarkar (LAD) er hyppigst affisert, og kun et fåtall har affeksjon av flere koronarkar med spontan koronar arteriedisseksjon $(7,10,11)$.

\section{Predisponerende faktorer og assosierte tilstander}

Flere faktorer og tilstander som disponerer for spontan koronar arteriedisseksjon har vært foreslått. Studier har vist at tilstanden forekommer hyppigere enn ellers hos pasienter som nettopp har født eller har vært eller er under behandling med hormonpreparater som antikonsepsjonsmidler, østrogener, progesteron, gonadotropiner og testosteron (5). Det er også sett økt forekomst hos dem som bruker sentralstimulerende midler, som kokain og amfetamin (5), og hos pasienter med vaskulitter og bindevevssykdommer $(5,10)$.

Hva som ligger bak de foregående predisponerende faktorene er ukjent, men én teori er økt stress på karveggen via katekolaminer, som ved høyt emosjonelt eller fysisk stress i forkant. Videre er det diskutert muligheten for underliggende vaskulær predisponering hos pasienter med underliggende systemsykdommer. Dette området er komplekst, og det er behov for mer forskning.

Den sterkeste sammenhengen er funnet mellom fibromuskulær dysplasi og spontan koronar arteriedisseksjon $(7,10,11)$. Fibromuskulær dysplasi er en ikke-inflammatorisk og ikke-aterosklerotisk sykdom som fører til stenoser, aneurismer og disseksjon av potensielt alle arterier i kroppen. Mest vanlig er affeksjon av renal-, carotis- og vertebralarteriene. Etiologien er ukjent, men genetisk predisposisjon antas å spille en rolle. Som hos pasienter med spontan koronar arteriedisseksjon rammes kvinner oftere enn menn, og hormonell påvirkning er fremhevet som mulig predisponerende faktor (12).

I flere studier er det sett klar sammenheng mellom disse tilstandene, særlig ved tilstedeværelse av slyngede koronarkar $(5-7,13)$. Det er ingen sikre tall på hvor stor andel av dem med fibromuskulær dysplasi som utvikler spontan koronar arteriedisseksjon. På grunn av den sterke sammenhengen mellom de to tilstandene (5) kan det være en god idé å screene pasienter for fibromuskulær dysplasi ved funn av spontan koronar arteriedisseksjon.

I en studie gjennomgikk man koronarangiografibildene fra pasienter diagnostisert med takotsubokardiomyopati, for å se etter kliniske likhetstrekk med spontan koronar arteriedisseksjon (14). Både ved takotsubokardiomyopati og spontan koronar arteriedisseksjon har pasientene ofte vært utsatt for emosjonelt stress. Man fant da flere med forandringer lik forandringene ved spontan koronar arteriedisseksjon som ikke var diagnostisert eller funnet initialt. I koronarkarene som var affisert av spontan koronar arteriedisseksjon, var det korresponderende områder med hypokinesi på ekkokardiografi. Det ble også her sett en sammenheng med fibromuskulær dysplasi. Det kan derfor være nyttig å se spesifikt etter spontan koronar arteriedisseksjon hos pasienter med takotsubokardiomyopati. Supplerende diagnostikk med optisk koherens-tomografi og/ eller intravaskulær ultralyd kan være nyttig i tvilstilfeller (14).

I ramme 1 er det et eksempel på en pasienthistorie.

\section{Behandling og prognose}

Tidligere ble pasienter med spontan koronar arteriedisseksjon hovedsakelig behandlet med perkutan koronar intervensjon. Nyere retrospektive og prospektive studier har vist at denne behandlingen ofte er mislykket og gir en høyere komplikasjonsrate enn konservativ tilnærming $(11,15,16)$. I en studie med 189 pasienter fra Mayo-klinikken var PCI-behandling av spontan koronar arteriedisseksjon mislykket hos $53 \%$ (11). Dette skyldes hovedsakelig at den murale hematomutbredelsen både i proksimal og distal retning øker ved ballongdilatasjon og/eller stentplassering. I tillegg er det stor risiko for iatrogen disseksjon ved katetermanipulasjon i en allerede skjør karvegg (16). Disse mulige komplikasjonene ved perkutan koronar intervensjon gir en betydelig risiko for akutt hjerteoperasjon $(11,16)$.

Ved konservativ tilnærming er det i studier gjort kontrollkoronarangiografi som viser at forandringene sett ved spontan koronar arteriedisseksjon gjerne normaliseres $(5,11)$. Komplett normalisering av koronarkaret er ofte sett etter fire uker (16).

Den nåværende anbefaling ut fra studier og kasuistikker bør derfor være primær konservativ medikamentell behandling, da dette trolig gir mindre komplikasjoner i tidlig fase og like gode langtidsresultater. Dette forutsetter sikker diagnose og hemodynamisk stabil pasient med normal blodstrøm. Hovedproblemet ved å velge konservativ tilnærming er risikoen for progrediering av den spontane koronare arteriedisseksjonen med ledsagende reinfarsering $(10,11)$. I en prospektiv studie med 280 pasienter ble $83 \%$ behandlet konservativt. Det var kun 3,5\% av 


\section{RAMME 1}

\section{En pasienthistorie}

En tidligere frisk kvinne i 50-årene ble innlagt ved et universitetssykehus med koronarsuspekte brystsmerter. Hun hadde ingen risikofaktorer for aterosklerotisk hjertesykdom, men hadde før hun fikk brystsmertene badet $\mathrm{i}$ iskaldt vann.

Pasienten hadde normale funn på EKG og ekkokardiografi. Blodprøver viste troponin I-stigning til maks $1735 \mathrm{ng} / \mathrm{l} /<15 \mathrm{ng} / \mathrm{l}$ ). Hun hadde en episode med ikke-persisterende ventrikkeltakykardi etter innleggelsen. Koronarangiografi viste langstrakt stenotisk parti i distale ramus circumflexus-arterien (RCX), med normal blodstrøm og uten tegn til aterosklerose i resten av koronarkarene. De angiografiske forandringene som ble funnet var typiske for spontan koronar arteriedisseksjon. Pasienten ble utskrevet med medikamentell behandling, uten behov for perkutan koronar intervensjon.

Kontrollangiografi etter seks uker viste tilnærmet normalisering av forandringene. I tillegg ble det utført angiografi av nyreog bekkenkar, uten funn av fibromuskulær dysplasi.

Pasienten fikk behandling med acetylsalisylsyre, klopidogrel og betablokker. Klopidogrelbehandlingen ble avsluttet etter at kontrollangiografi viste normalisert koronarkar.

disse som fikk residiv og trengte påfølgende revaskularisering med perkutan koronar intervensjon eller akutt hjertekirurgi ved samme innleggelse (17).

På bakgrunn av fare for residiv på kort sikt ved konservativ tilnærming anbefales det observasjon av pasienten i 3-5 dager i sykehus (16). Ved nye iskemiske hendelser må man alltid revurdere behovet for perkutan koronar intervensjon eller koronararteriebypasskirurgi $(15,16)$.

Basert på de foreliggende studiene om spontan koronar arteriedisseksjon er acetylsalisylsyre og betablokker foreslått medikamentell behandling (16). Klopidogrel anbefales i opptil 12 måneder eller til normalisering av forandringene ved kontrollkoronarangiografi (16). ACE-hemmer anbefales hos pasienter med nedsatt venstre ventrikkel-funksjon $(5,10)$. Statiner er kun anbefalt ved dyslipidemi, da det er sett høyere residiv av spontan koronar arteriedisseksjon ved statinbruk $(5,10)$. Det foreligger ikke data om bruk av glyserolnitrater eller kalsiumantagonister.

\section{Konklusjon og anbefaling}

Spontan koronar arteriedisseksjon er en sjelden, men viktig årsak til akutt koronarsyndrom. Ut fra nåværende studier anbefales konservativ tilnærming ved funn av forandringer som er typiske for spontan koronar arteriedisseksjon, forutsatt stabil hemodynamikk og normal blodstrøm i karet $(16,18)$.

Det er viktig at man er oppmerksom på tilstanden som årsak til akutt koronarsyndrom, da det hos disse pasientene er økt komplikasjonsfare ved perkutan koronar intervensjon. Den videre behandlings- og oppfølgingsstrategien er også forskjellig fra den ved klassisk aterosklerotisk akutt koronarsyndrom.

Pasienten har gitt samtykke til at artikkelen blir publisert.

\section{Charlotte Sæland (f. 1986)}

er lege i spesialisering i indremedisin og under grenspesialisering i kardiologi.

Forfatter har fylt ut ICMJE-skjemaet og oppgir ingen interessekonflikter.

\section{Tor Melberg (f. 1958)}

er ph.d., spesialist i hjertesykdommer med spesialkompetanse innen invasiv kardiologi og avdelingssjef.

Forfatter har fylt ut ICMJE-skjemaet og oppgir ingen interessekonflikter.

\section{Nigussie Bogale (f. 1972)}

er ph.d, fellow of European Society of Cardiology, spesialist i hjertesykdommer med spesialkompetanse innen invasiv kardiologi og overlege.

Forfatter har fylt ut ICMJE-skjemaet og oppgir ingen interessekonflikter.

\section{Litteratur}

1. Mortensen KH, Thuesen L, Kristensen IB et al. Spontaneous coronary artery dissection: a Western Denmark Heart Registry study. Catheter Cardiovasc Interv 2009; 74: 710-7.
2. Nishiguchi T, Tanaka A, Ozaki Y et al. Prevalence of spontaneous coronary artery dissection in patients with acute coronary syndrome. Eur Heart J Acute Cardiovasc Care 2016; 5: 263-70.

3. Vrints CJ. Spontaneous coronary artery dissection. Heart 2010; 96: 801-8.

4. Pretty $\mathrm{H}$. Dissecting aneurysm of coronary artery in a woman aged 42. BMJ 1931; 1: 667

5. Saw J, Aymong E, Sedlak T et al. Spontaneous coronary artery dissection: association with predisposing arteriopathies and precipitating stressors and cardiovascular outcomes. Circ Cardiovasc Interv 2014; 7: 645-55

6. Saw J, Aymong E, Mancini GB et al. Nonatherosclerotic coronary artery disease in young women. Can J Cardiol 2014: 30: 814-9.

7. Saw J, Ricci D, Starovoytov A et al. Spontaneous coronary artery dissection: prevalence of predisposing conditions including fibromuscular dysplasia in a tertiary center cohort. JACC Cardiovasc Interv 2013; 6: 44-52.

8. Saw J, Mancini GB, Humphries K et al. Angiographic appearance of spontaneous coronary artery dissection with intramural hematoma proven on intracoronary imaging. Catheter Cardiovasc Interv 2016: 87: E54-61.

9. Yip A, Saw J. Spontaneous coronary artery dissection - A review. Cardiovasc Diagn Ther 2015; 5: 37-48.

10. Tweet MS, Hayes SN, Pitta SR et al. Clinical features, management, and prognosis of spontaneous coronary artery dissection. Circulation 2012; 126: 579-88.

11. Tweet MS, Eleid MF, Best PJ et al. Spontaneous coronary artery dissection: revascularization versus conservative therapy. Circ Cardiovasc Interv 2014; 7: 777-86.

12. Michelis KC, Olin JW, Kadian-Dodov D et al. Coronary artery manifestations of fibromuscular dysplasia. J Am Coll Cardiol 2014; 64: 1033-46.

13. Eleid MF, Guddeti RR, Tweet MS et al. Coronary artery tortuosity in spontaneous coronary artery dissection: angiographic characteristics and clinical implications. Circ Cardiovasc Interv 2014; 7 : 656-62.

14. Chou AY, Sedlak T, Aymong E et al. Spontaneous Coronary Artery Dissection Misdiagnosed as Takotsubo Cardiomyopathy: A Case Series. Can J Cardiol 2015; 31: 1073 e5-8.

15. Alfonso F, Paulo M, Lennie V et al. Spontaneous coronary artery dissection: long-term follow-up of a large series of patients prospectively managed with a «conservative» therapeutic strategy. JACC Cardiovasc Interv 2012; 5: 1062-70.

16. Saw J, Mancini GB, Humphries KH. Contemporary Review on Spontaneous Coronary Artery Dissection. J Am Coll Cardiol 2016; 68: 297-312.

17. Saw J, Prakash R, Starovoytov A et al. Cardiovascular outcomes in a large prospectively followed single-center cohort of spontaneous coronary artery dissection patients. J Am Coll Cardiol 2016 67: 457 .

18. Mehta LS, Beckie TM, DeVon HA et al. Acute Myocardial Infarction in Women: A Scientific Statement From the American Heart Association. Circulation 2016; 133: 916-47.

Mottatt 12.2. 2016, første revisjon innsendt 8.7. 2016 godkjent 24.2. 2017. Redaktør: Liv-Ellen Vangsnes. 